\title{
Collision Risk with High Speed Vessels
}

\section{Andrew Mills}

I. IN T R O D U C T I ON. Following Dag Pike's earlier paper ${ }^{1}$ on this subject I would like to discuss some points and address the problems of collision avoidance with High Speed Vessels within the framework of the present International Regulations for the Prevention of Collisions at Sea (colregs). ${ }^{2}$ Generally, a valid case for limited modifications to the COLREGS may be presented, but they may not be as wanting as suggested by Mr Pike.

'1. SPEED. Whilst one cannot argue with Mr Pike's interpretation of the time factors involved and the risk these impose on vessels, the colregs are clear on factors to be considered for adopting a safe speed for any vessel, on passage, or where a risk of collision may exist. Those most pertinent to my discussion are the following two extracts from COLREg Rule 6: 'Safe Speed'.

(a) (ii). The traffic density including concentrations of fishing vessels or any other vessels.

(a) (iii). The manoeuvrability of the vessel with special reference to stopping distance and turning ability in the prevailing conditions.

Importantly, the above, rather than setting a permanent numerical safe speed for High Speed Vessels mentioned as a possible solution, allows the Master or Officer of the Watch of a High Speed Vessel to judge a proper safe speed tailored to his vessel's size, type and manoeuvrability for the situation. This freedom of self-determination of safe speed is essential for future application as, at best, 'High Speed Craft' is a loose term and is set to become even more ambiguous in the near future as a greater number of these vessel proliferate.

To draw an analogy, a High Speed Vessel is not going to run at full speed through an area of high traffic density any more than a small coaster will reach full speed in the Solent during a Summer Sunday. Quite simply, a safe speed is one that minimizes risk of collision, even if it is fully stopped.

3. COURSE. For the purposes of the colregs, alterations of course are only required when a risk of collision or a close-quarters situation is deemed to exist. By an early appraisal of approaching traffic density, an alteration of course can be effected which will not place a High Speed Vessel in a situation which would lead to closequarters encounters where course alterations would need to be taken, so keeping the vessels involved away from the attending dangers.

In the same way, a slower commercial vessel gives concentrations of fishing vessels a wide berth as opposed to sailing through them, regardless of whether they are actually engaged in fishing or steaming.

This is indeed the current practice of High Speed Vessels when approaching slower vessels, and a commercial vessel does not offer the same unpredictability of behaviour as does a fishing vessel. With adequate sea-room and the present state of development of High Speed Vessels, I feel the risk of collision is adequately addressed under the existing COLREGs bearing in mind that alterations of course and speed can be combined to avoid collision.

4. CONSTRICTED WATERS. Of course the whole problem of collision avoidance changes in regularly constricted and busy waters, and this is where the colREgs are open to modification. On an international level there would appear to be an excellent case for a system of 'Marine Traffic Control' in specified areas so that safe routeing of all vessels 
could be organized, thus allowing High Speed Vessels to operate to their full potential. It could be argued that this is only a further evolution of the already existing colreg Rule Io: 'Traffic Separation Schemes', but it would require amendment to accommodate and define such areas as well as the question of vessel identification.

Additionally, the above conditions can apply in areas administered by government and harbour authorities so that the onus would fall on them to change their regulations and Vessel Traffic Services. However, these local regulations are required by the colregs to conform as closely as possible to them, and therefore an international precedent would still need to be legislated for by the International Maritime Organization.

5. IDENTIFICATION. On the point of identification, a recent amendment to the COLREgs has allowed a repositioning of navigation lights to identify High Speed Craft (Annex I, Rule I 3 ) which states: 'The masthead light of a high speed craft with a length to breadth ratio of less than $3^{\circ} \circ$ may be placed at a height related to the breadth of the craft lower than that prescribed in Paragraph $2(a)$ (i) of this annex, provided that the base angle of the isosceles triangles formed by the sidelights and masthead light, when seen in end elevation, is not less than 27 degrees'.

However, the problem here is the expression 'may be...' as opposed to 'required to be...'. Also it could be argued that even this form of identification is not as clear as it needs to be to guarantee quick and easy visual recognition of a High Speed Vessel. It is one rule that does not go far enough.

Finally, whilst generally defending the colregs and their application to High Speed Vessels as they stand, changes can be, and should be, made at international level and hence harbour authority level for the conduct of such vessels in confined waters and for identification.

6. CONCLUSION. The International Maritime Organization has had to legislate and standardize requirements for recent developments in Marine Technology (for example ECDIS), and the High Speed Vessel is just another example of a developing challenge to navigation. The generic question, really, is where will the commercial considerations of speed begin to take precedence over the safety of life at sea? If indeed there is to be a conflict at all?

\section{REFEREN CES}

1 Pike, D. (1995). Collision risk with fast ferries. This Journal, 48, 436.

${ }^{2}$ International Regulations for the Prevention of Collisions at Sea. (1972). International Maritime Organization.

\section{KEY WORDS}
1. Collision avoidance.
2. Fast ferries.
3. High speed vessels. 